EPiC Series in Engineering
Volume 3, 2018, Pages 941-949
HIC 2018. 13th International
Conference on Hydroinformatics

\title{
Floodbook: a social platform for flood hydrology
}

\author{
Silvia Isacco ${ }^{1}$, Pierluigi Claps $^{1}$, Susanna Grasso ${ }^{1}$, Ennio Ferrari ${ }^{3}$, Maria \\ Bernadette Guercio ${ }^{3}$, Rosaria Ester Musumeci², Graziella Emanuela \\ Scarcella $^{3}$, Pasquale Versace ${ }^{3}$, Francesco Laio ${ }^{1}$ \\ ${ }^{1}$ Politecnico di Torino, Turin, Italy \\ ${ }^{2}$ University of Catania, Catania, Italy \\ ${ }^{3}$ University of Calabria, Rende (CS), Italy \\ silvia.isacco@polito.it
}

\begin{abstract}
New technologies provide a new great source of information, increasing the available knowledge in many different fields, including hydrology. With this work we wish to share with the Hydroinformatics community an attempt in the direction of using the social media to increase the general understanding of the areas affected by flooding events in Italy. We have developed "Floodbook", an online platform aimed at constituting a database for flood-damaged areas in Italy, trying to fill the knowledge gap of flood events occurring in small and ungauged basins. The platform invites citizens to contribute posting geotagged contents, photos or videos, on the social media; these contents are collected and elaborated to provide a clear, yet rigorous and comprehensive, picture of the event. Some case studies are described to show how this data collection can be used to improve flood extent assessment and flood dynamics reconstruction.
\end{abstract}

\section{Introduction and state of the art}

Floods are the most damaging and widespread natural hazard that affect people in the world [1]. According to the UN Office for Disaster Risk Reduction more than 2 billion of people were involved in floods in the last 20 years [1]. Climate change and increasing anthropization are making the protection of people and properties from floods even more challenging than ever. In Italy people affected were about 600000 in the last century, counting casualties, fatalities and evacuees [2]. A considerable part of floods damages is attributable to events happening in small, ungauged and sometimes remote areas. This comes up with the wide gap in the observation network on minor hydrography, which keep these areas also out of the main flood hazard maps available now for most European countries. New technologies can be of help in improving the knowledge of inundation 
phenomena throughout the whole territory, enabling the collection of crowd-sourcing (CS) and volunteered geographic information (VGI) for flood hazard evaluation. In fact, every smartphone-user can be seen as a mobile sensor, that can provide geotagged data, mostly in the form of photos or videos. New archives can be built from information generated from smartphones and shared on the web, providing new data which can support the standard data and tools for flood risk management and land use planning.

The collection of scientific data from individuals or organizations is often called "crowd-sourcing". The spread of crowd-sourcing in flood hydrology is a relatively recent approach. However, the concept of citizen science is antecedent to the diffusion of web connected devices. We find examples of participative rain monitoring since the 1990s, as the CoCoRaHS [2] and the Rainlog projects [3], while in the early 2000 the application of VGI for rapid flood damage estimation is compared to estimates based on hydraulic modelling [4]. One of the first applications in projects designed to reconstruct specific flood events dates back to the 2011 Queensland Floods [5]. More organized platforms consist in evolving from single case studies to a permanent citizens' observatory, as for example the one developed in Brazil through the AGORA project [6] or the European WeSenselt project [7]. Several purpose-built apps are also available, mostly for real time flood management, for citizens and decision makers use: we mention Floodis [8] and WeSenseIt [7]. Other studies are now investigating how to use information posted on the social-media for rapid inundation mapping [9][10] and even to predict floods [11]. In this multi-disciplinary arena, the Floodbook project aims also to introduce a knowledge-based control and complement to the collection and organization of occasional observations, adding formal mapping attributes, as e.g. flood risk contour lines, that help building a more thorough perception of the nature of events.

\section{Floodbook description}

In the past, an inventory of floods occurred in Italy was carried out by the National Group for Prevention of Hydrogeologic Hazards in the framework of the AVI project [12]. A database of all Italian locations hit by floods from the 1918 to the 1990 was created through a systematic analysis of newspapers, publications and local press. The AVI project aimed at being a powerful instrument to describe the hydrogeological risk at national level. The inventory was effectively used in order to define the floodplains essentials for spatial planning and land management. Since that project, many attempts of creating detailed database were made, both at regional and national level [13]

The multi-source online platform "Floodbook" comes as the ideal continuation of the AVI project in the Web 2.0 era. The goal of the "Floodbook" project is to gather data located in space and time about floods in Italy, especially covering small and marginal basins. The idea is to collect information from different sources, that will be merged in an online map after validation. We will base our analysis both on active and passive crowdsourcing. We call active crowd-sourcing (active CS) the approach in which the user produces voluntary geographical information (VGI) for a specific purpose he is aware of. Passive crowdsourcing (passive CS) consists in filtering and processing the mass of information spontaneously shared on the web by means of specific algorithms. The advantage of passive crowdsourcing resides in the amount of information available, at the expense of quality. Active crowdsourcing produces information structured to match specific requirements, but with the higher efforts of engaging a significant number of users.

The attention will be first focused on active CS, getting the support of local stakeholders (i.e., majors, civil protection agencies, academic community, technical structures of municipalities, citizen associations) to engage citizens in a responsible contribution [14].

Social media information are widely investigated in recent works, in order to map flood extension or to predict the impact of floods. The most used social media in recruiting information during or after 
an emergency event is Twitter $\AA$, because data are easily available [15]. However, focusing on a specific social network we would end up losing part of the potential contributors. For example, we can not ignore that Facebook ${ }^{\circledR}$ is the most popular social network in Italy.

The proposed scheme is based on Crowdmap ${ }^{\circledR}$, a sharing platform sponsored by Ushahidi, to organize the content gathered through:

- Twitter ${ }^{\circledR}$, activating the reception of specific hashtags (for example "floodbook")

- $\quad$ Facebook ${ }^{\circledR}$, with a chatbot for Facebook Messenger ${ }^{\circledR}$ (see Figure 1)

- The "Floodbook" website, by compiling an online form

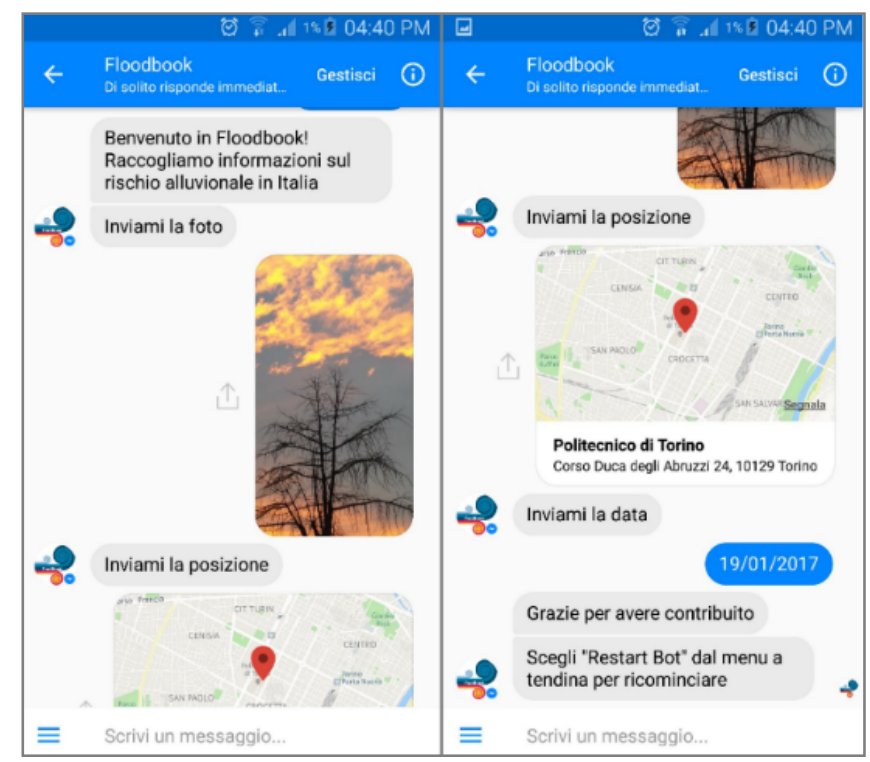

Figure 1: Example of Facebook Messenger ${ }^{\circledR}$ chatbot (in Italian), that guides the user through the submission of the VGI

The purpose of the multi-source approach is to achieve a considerable number of structured data, involving as many users as possible. Users are guided to produce a report answering questions about "what, when and where". The information is stored in standard forms, reporting local coordinates, place name info, date, time, type of event and water course of interest (see Figure 2). If rainfall data is available, the content sent by citizens is enhanced with additional information about rainfall depth related to the documented event. 


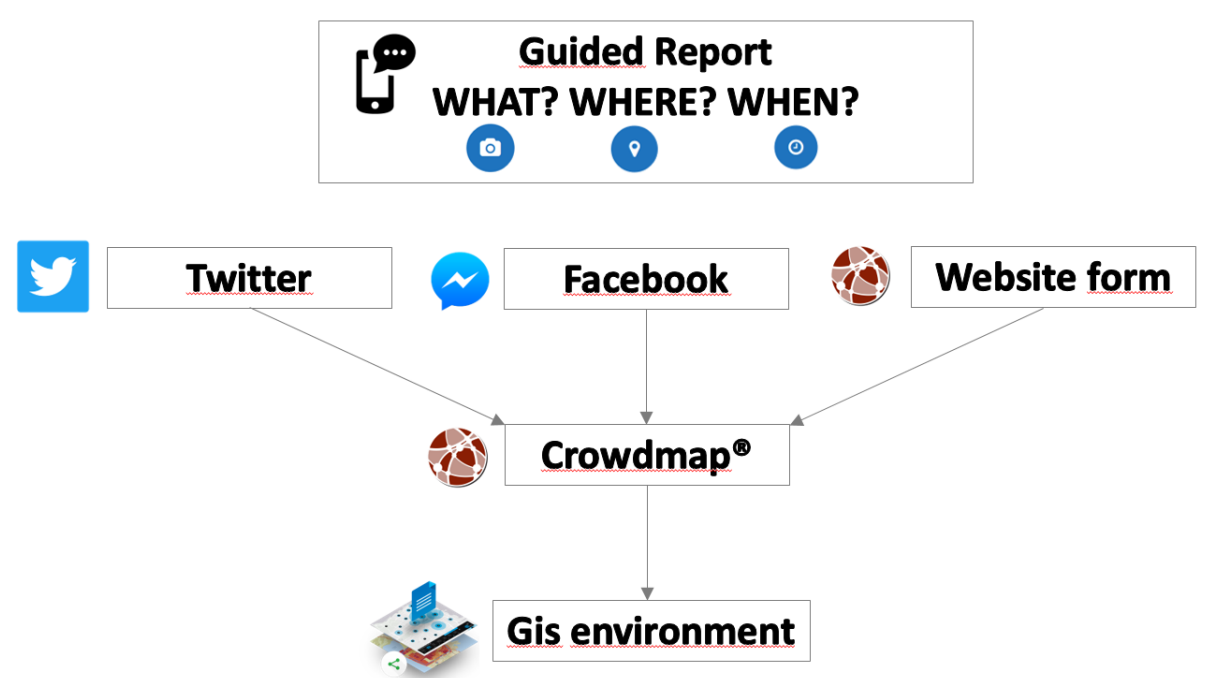

Figure 2: Crowdmap ${ }^{\circledR}$ use in Floodbook to organize data from different receptors. Users can send informations to any of the social channels listed above

\section{Pilot application to recent flood events in Italy}

We consider the pilot case of the November 2016 flood in North-Western Italy in order to show the potential of Floodbook. The town of Moncalieri was selected as an interesting case study, because of its peculiar role played in the event. The town is located at the confluence of threerivers, the Po, the Chisola and the Sangone and was hit in Novembre 2016 by a severe inundation, whose dynamics was initially unclear. In particular, some of the flooded areas, many of them with urban and commercial settlements, were not assumed as being prone to flood risk, and remote sensing products did not document their actual degree of flooding. Because of these issues, traditional data sources appeared to be inadequate to completely describe the flooding event and the Authority in charge of the damage responsibility deemed necessary to investigate all available information also through unconventional channels. During the days of the flooding, social media users were really active in witnessing the evolution of the event, allowing us to build a mapped history of the inundation. From the traditional analysis, we found three different causes of flooding: spreading of flooding of the Chisola in not embanked areas upstream of the town, levee breaking of the Chisola near the town, and backwater effects from the Po River. The causes of flooding in the different areas of the town and the actual flow paths were investigated and finally clarified using passive CS thanks to the social media reports extracted from Facebook ${ }^{\circledR}$, Twitter ${ }^{\circledR}$ and online newspaper. Floodbook was, in this case, a technical tool used to answer most of the questions regarding lack of knowledge about the actual hydraulic paths of water in the town and about vulnerable nodes in the protection infrastructures.

In order to show the potential of Floodbook and the expected contributions, similar analysis can be extended to other case studies, simulating reports sent by citizens during or after the event (Table 1). 


\begin{tabular}{lr}
\hline Location & Year \\
\hline Messina (Sicily) & October 2009 \\
Sardegna (Sardinia) & November 2013 \\
Rossano e Corigliano (Calabria) & August 2015 \\
Moncalieri (Piedmont) & November 2016 \\
\hline
\end{tabular}

Table 1: Flood events considered in Floodbook

Media material has been collected through Twitter ${ }^{\circledR}$, Facebook ${ }^{\circledR}$, Youtube ${ }^{\circledR}$, witnesses' report and online newspapers. The result (Figure 3) is published on the website project www.floodbook.it. The local information turned out to be complementary to other sources of information, commonly available, as satellite imagery. The integrated use of different data allowed the reconstruction of flood extent and dynamics, and highlighted some critical situations. Furthermore, we were able to identify the configuration of different flood paths.

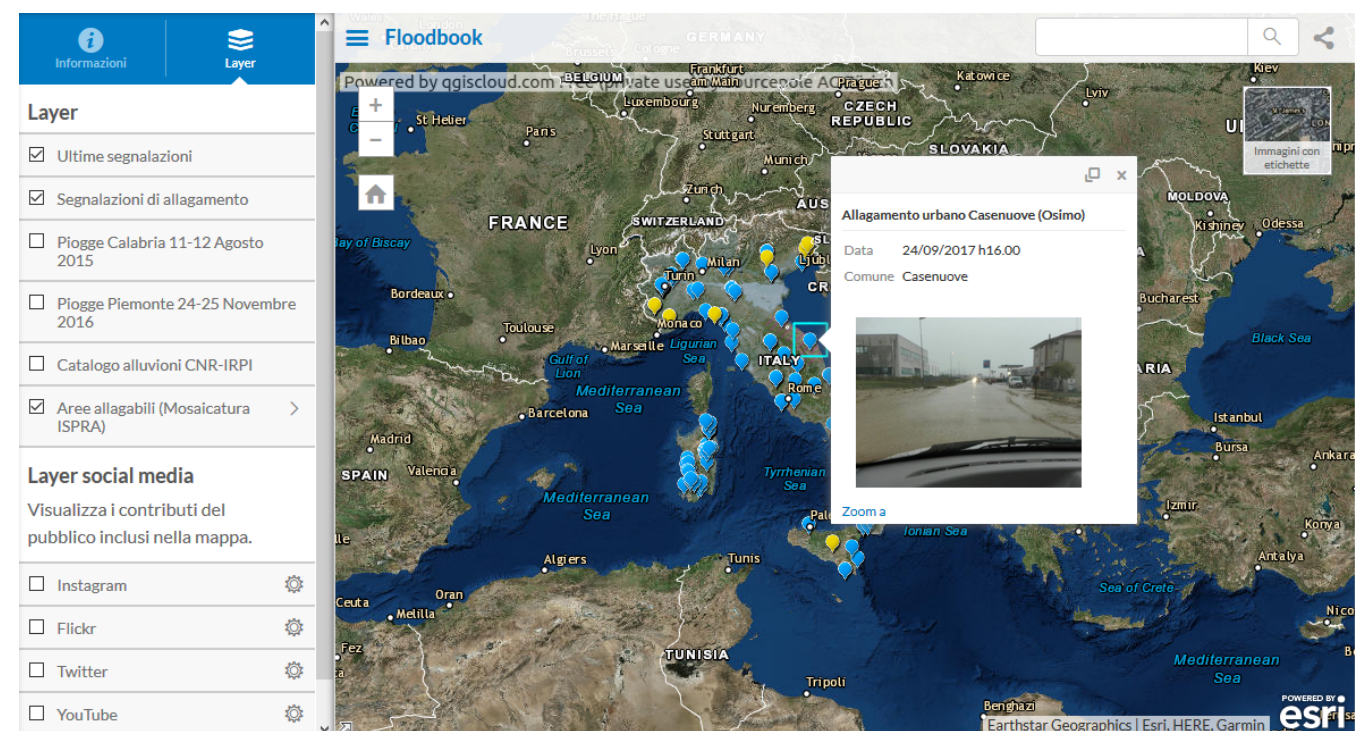

Figure 3: Floodbook Web-GIS representation (www.floodbook.it)

\section{Strategy of engagement}

The Floodbook channel was published on December 2017, with the dual aims of promoting the awareness of hydrogeological risk and collecting data about minor events. The very crucial factor for ensuring the success of the project is the involvement and the awareness of citizens to provide VGI about floods.

In the time being, we can identify two main obstacles in the engagement of people:

1) The saturation of social media, which causes the difficulty for a new project to be known without paying high sponsorship costs 
2) The discontinuous and random nature of flood events, which makes it impossible to focus on the raise of awareness of people belonging to a specific geographical area

Considering the above limitation, to achieve a reasonable spread on the whole country we adopted the strategy to interface with stakeholders distributed throughout the territory who would act as intermediate interlocutors between "Floodbook" and the users. We identified as key subjects: i) the Mayors, asked to promote the submission of VGI by the citizenship as their favorite channel for future security works; ii) the Civil Protection local agencies, which operate during the emergencies; iii) public or private bodies who have technical knowledge about the smaller parts of the drainage networks, as e.g. forest rangers or environmental associations, engineering, students etc.

The strategy for engaging users in contributing to the project is pursuived also through the creation of an online network of people, that join the cause and spread the word about Floodbook information collection. The network was built through affiliation to other social media thematic pages, in order to mutually benefit of the communities of followers.

To undertake a link with official web channels, as e.g. web pages of national environmental associations, was not successful. The reason of this failure lies in the content directionality of these web pages: national web channels offer information to a wide public but in a one-way direction. Usually, contents published on official pages are produced by a team of administrators. The transfer of information is from the page to the users, who are simple receivers and are not expecting to receive a response channel to contribute their whatever knowledge.

On the other hand, we found fruitful to get in touch with local entities web pages that have a good number of followers. In particular, we selected a list of thematic pages and we established a contact with those having an environmental character, as local blogs and online newspapers. These secondary web channels provide examples of a long-standing crowd-sourcing mechanism. The community of followers is used to contributing towards the creation of contents that are published on the web pages. Animating the production of contents by these groups on flood themes is a relatively simple operation. For example, we found that meteorologic amateur groups involve a considerable number of people in production of media about the effects of severe weather. While the flood topic is an emergencial and discontinuos event, weather conditions are always checked by people, and this topic counts on a loyal network. These entities, who act exclusively through social network channels, are very interested in collaboration for the creation of new contents and in maintaining their profile active. A similar motivation is also fruitful in the collaboration with online local press agencies, in which nonprofessional journalist teams need monitoring facts about their territory.

The second step undertaken for the development of Floodbook was the creation of a community of people covering the entire national territory. We engaged, where possible, a responsible for each region. The role of the responsible is covered by researchers, administrators of social network pages or simply passionate people. All these subjects constitutes the Floodbook community. In order to constantly monitor the inundation events on the country, the Google Alert's service is used. After the notification of a flood, the responsible of the region is contacted in order to encourage local web sites in promoting the use of the Floodbook tool to communicate damages or local phenomena. 


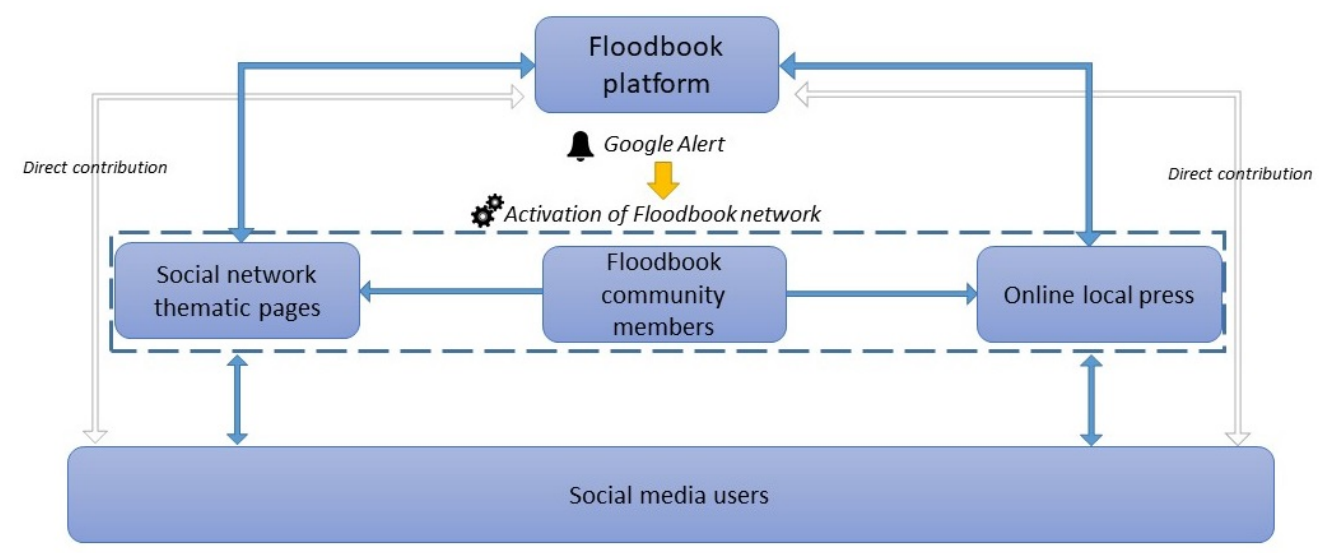

Figure 4: The "Floodbook" network

For example, during the event of December 2017 that struck the Tuscany and Emilia - Romagna regions, meteorological local pages of the Floodbook network were alerted in order to contribute to the project. All the contents received by affiliated pages containing media about the flood were marked by the hashtag \#floodbook. In this way, we got a dual advantage: we gained a good visibility of the project and we increased the amount of collected material. In addition to what directly received from citizens through the Floodbook platform, we also were sent relevant content gathered by other channels.

It is now clear how the Floodbook project pursues the aim of unifying into a unique platform all the media with flood content addressed to the web in Italy and through different channels. Data directly sent from citizens are collected substantially through Facebook ${ }^{\circledR}$ and the website form. The media sent to our platform are mostly generated by private users, as called for by the project. However in some cases, we received reports generated from other users and already published on web-channels. These postswere highlighted and geolocalised by Floodbook followers to be reported on our online map. We called these contributions "indirect crowdsourcing" (ICS). ICS consists in the effort to concentrate and distributing information about floods, disseminated in various web sites, on the thematic platform "Floodbook". In particular, a great source of ICS is the italian website of citizen journalism "YouReporter.it", that allows users to upload videos about small pieces of news that do not become national cases. This basic concept appears to be the same sought after by the "Floodbook" platform concerning inundation events. Another preferential channel is the Web-TV Vigilfuoco.it. This latter website is organized as an information portal regarding the communication of the emergency actions carried out by the Italian National Corp of Fireworks. As part of the service of Civil Defence, it contains also a lot of aerial view of inundated areas.

In summary, we found that, in order to create an efficient crowdsourcing mechanism on a new project it is necessary at first to target specific stakeholders. The individual stakeholder spreads the new project to its own network, according to a pyramid scheme, in which the final users are private citizens. In order to create the sense of belonging to a community, a real network of people need to be built. Indeed, the involvement in crowdsourcing campaigns is strongly linked to the level of contact that people have with the project coordinators and other contributors [16]. 


\section{Conclusions}

This work aims at illustrating the potential of crowdsourced knowledge in the flood hazard field. The newborn platform "Floodbook" collects geotagged data from different social networks, with the aim of educating citizens in producing useful information, through the support of local stakeholder. An online map is the usual interface for accessing the information, where several case studies spread across Italy are shown. The cases we built show how information derived from citizen reports can provide additional information in flood analysis. The challenges to the success of the project are basically linked to the capacity to engage people in the project. In a second step, the great deal of information, already available on the web, appropriately filtered to exclude noise, will be more explicitly taken in account and merged with other standard and non-standard information. The joint use of active and passive CS will then provide a widespread coverage of the entire country, as a useful overview for both policy makers and scientists, in particular concerning the spatial distribution of flood events related to the smaller catchments. A very important focus of the project, in addition to data collection, is the dissemination of correct flood risk perception. Flood losses can be mitigated, not only through the increase of technical knowledge of the event causes, but in nurturing correct risk communication to common people. This last aspect has gained increasing interest in the flood risk management [17]. Risk communication is becoming an important field and is now seen by experts as an essential measure to lead to a real mitigation of flood impact. 


\section{References}

[1] J.I. Barredo, Major flood disasters in Europe: 1950-2005, Nat. Hazards 42 (2007) 125-148.

[2] Available at: http://www.cocorahs.org/. (Accessed January 1, 2016).

[3] Available at: https://www.wunderground.com/weatherstation/overview.asp. (Accessed December 9, 2016).

[4] K. Poser, D. Dransch, Volunteered geographic information for disaster management, with application to rapid flood damage estimation, Geomatica 641 (2007) 89-98.

[5] K. McDougall, Using Volunteered Information to Map the Queensland Floods, Proceedings of the surveying \& spatial sciences biennial conference 2011, 21-25 November 2011, Wellington, New Zealand.

[6] F.E.A. Horita, J.P. de Albuquerque, L.C. Degrossi, E.M. Mendiondo, J. Ueyama, Development of a spatial decision support system for flood risk management in Brazil that combines volunteered geographic information with wireless sensor networks, Computers \& Geosciences VL 80 (2015) 8494.

[7] V. Lanfranchi, S. Wrigley, N. Ireson, F. Ciravegna, U. Wehn, Citizens' Observatories for Situation Awareness in Flooding, 11th International ISCRAM Conference, Information Systems for Crisis and Response Management (2014).

[8] C. Rossi, A. Favenza, F. Scullino, V. Macchia, G.L. Spoto, F. Dominici, Evaluating FLOODIS: Mobile Sensing for a Flood, International conference on cloud technologies and applications (cloudtech

15) Emergency Service in the Cloud (2015).

[9] D. Fohringer, H. Dransch, H. Kreibich, K. Schröter, Social media as an information source for rapid flood inundation mapping, Nat. Hazards Earth Syst. Sci. 15 (2015) 2725-2738.

[10] T. Brouwer, D. Eilander, A. Van Loenen, M.J. Booij, K.M. Wijnberg, J.S. Verkade, J. Wagemaker, Probabilistic flood extent estimates from social media flood observations, Nat. Hazards Earth Syst. Sci. 17 (2017) 735-747.

[11] N. Tkachenko, S. Jarvis, R. Procter, Predicting floods with Flickr tags, PLoS ONE 12(2) (2017).

[12] F. Guzzetti , M. Cardinali, P. Reichenbach The AVI Project: a bibliographical and archive inventory of landslides and floods in Italy. Environ Management 18(4) (1994) 623-633.

[13] E. Napolitano, I. Marchesini, P. Salvati, M. Donnini, C. Bianchi, F. Guzzetti, LAND-deFeND An innovative database structure for landslides and floods and their consequences, Journal of Environmental Management, Volume 207 (2018) 203-218.

[14] J. Le Coz, A. Patalano, D. Collins, N. Federico Guillen, C. Marcelo Garcia, G.M. Smart, J. Bind, A. Chiaverini, R. Le Boursicaud, G. Dramais, I. Braud, Crowdsourced data for flood hydrology: Feedback from recent citizen science projects in Argentina, France and New Zealand, J. Hydrol. 541 (2016) 766-777.

[15] T. Simon, A. Goldberg, B. Adini, Socializing in emergencies - A review of the use of social media in emergency situations, Int. J. Inform. Manage. 35 (2015) 609-619.

[16] A. Baruch, A. May, D. Yu, The motivations, enablers and barriers for voluntary participation in an online crowdsourcing platform,Computers in Human Behavior,Volume 64 (2016) 923-931.

[17] W. Kellens,T. Terpstra, P. De Maeyer, Perception and communication of flood risks: a systematic review of empirical research, Risk Anal. 2013 Jan; 33(1):24-49. 